\title{
Determining the Priority of Medical Equipment Maintenance with Analytical Hierarchy Process
}

\author{
https://doi.org/10.3991/ijoe.v15i10.10920
}

\author{
Alfa Omega Hutagalung ${ }^{(凶)}$, Sawarni Hasibuan \\ Mercu Buana University, Ibukota Jakarta, \\ alfao.htg@gmail.com
}

\begin{abstract}
The best quality of services provided by health care facilities can be realized if medical devices are in reliable and safe condition. The large number of medical devices and the use of various types of medical devices have been a problem for hospital management to decide the level of priority in carrying out medical equipment maintenance. The purpose of the maintenance is to increase their availability and to reduce the maintenance costs. This study aims to show how to determine the priority level of medical device maintenance based on the calculation of the criticality scores of medical devices. The criticality scores are obtained based on the assessment of criteria, sub-criteria and grade by using the method of Analytical Hierarchy Process (AHP). The devices with higher critical weight take higher priority for maintenance than devices with lower critical weight. The approach was applied for 20 medical devices at Out Patient Department of Eye Hospital in Jakarta to describe how to prioritize the maintenance of medical devices.
\end{abstract}

Keywords-AHP; Maintenance; Medical Devices; Criterion; Criticality Scores

\section{$1 \quad$ Introduction}

Hospitals are the main institutions that play an important role in providing health services to the community. In an effort to provide quality services, one of the factors that needs to be addressed by hospital management is the availability of wellfunctioning health equipment. The increasing number and complexity of medical equipment requires hospitals to set and manage management of medical equipment in a manner that ensures that important medical equipment is safe and reliable and operates at the required level of performance. Decisions taken to determine the strategy of medical equipment maintenance are not only based on recommendations from manufacturers but must also consider a more efficient and cost-effective maintenance strategy.

Multi-criteria decision making model has been widely used to prioritize medical devices and establish guidelines for choosing the right maintenance strategy. Multicriteria decision making is a commonly used branch of decision making, which is divided into multi objective and multi criteria decision making. ${ }^{1}$ Multi-attribute decision making by determining preference decisions such as evaluation, prioritization, 
and selection of alternatives available based on several attributes. Analytical Hierarchy Process (AHP) is a measurement theory through paired comparisons depend on the judgment of experts to rank the level of priority. ${ }^{2}$ Taghipour et $\mathrm{al}^{3}{ }^{4}$ used the AHP method to classify medical devices according to their critical level. Criticality is calculated based on the criteria and sub criteria weights and the assessment of the intensity of the grade, criteria and sub criteria. The strategy of medical equipment maintenance must be carried out according to available resources, in terms of budget, human resources, and equipment. According to Ivlev, ${ }^{5}$ multi criteria decision analysis techniques that can be applied to the maintenance of medical equipment are AHP and Analytic Network Process (ANP) to calculate the weight of criteria based on expert judgment, and Elimination and Choice Expressing Reality (ELECTRE) and TOPSIS techniques to classify and determine the order of maintenance strategies. Jamshidi et $\mathrm{al}^{6}$ used a fuzzy multi-criteria decision making approach to prioritize medical devices based on different expert opinions and consider uncertainty. They then proposed a maintenance planning diagram to identify adequate maintenance strategies for each device based on the total score of the multi-criteria analysis and priority index of the risk. Ben Houria et $\mathrm{al}^{7}$ presented quantitative techniques with the AHP, TOPSIS and MILP method to determine the choice in medical care management. They used the AHP method to determine the critical score for each medical device, the TOPSIS method was used to determine the order of strategies for maintaining medical equipment and in the final stage, the MILP method was used to select the medical equipment maintenance strategy.

The research applies a multi-criteria decision-making model that can be used to prioritize medical devices and establish guidelines for choosing the right maintenance strategy using the method of Analytical Hierarchy Process (AHP). This method has been selected for extensive application in various industries and quality are evident in determining the priority selection that includes assessment experts both on the proposed criteria. The purpose of this study is to determine the criteria and criteria for medical devices and the criticality scores of each devices so that the priority scale can be determined to make maintenance decisions at JEC Eye Hospital in Jakarta.

\section{$2 \quad$ Literature Review}

\subsection{Maintenance}

Maintenance is all actions appropriate for retaining an item/part/equipment in, or restoring it to, a given condition. ${ }^{8}$ Adjustments or replacements needed to ensure the conditio in accordance with the existing plan. Heizer and Render $^{9}$ stated that maintenance is all activities involved in keeping a system's equipment in working order.. Sehwarat and Narang ${ }^{10}$ stated that the maintenance is a work performed sequentially to maintain or improve existing facility so as to comply with standards (in accordance with the functional and quality). 


\subsection{Medical Devices}

According to Regulation of Indonesian Minister of Health No. 1191/2010, ${ }^{11}$ the definition of medical devices, namely instruments, apparatus, machines, implants that do not contain elements of drugs, function or are used to prevent, diagnose, cure and alleviate diseases, treat sick people and restore human health and to form structures and repair body function. The classification of medical devices refers to those as stipulated in Regulation of Indonesian Minister of Health No. 118 concerning the Compendium of Medical Devices, ${ }^{12}$ consisting of 3 types, namely Electromedical, Non Electromedical and In Vitro Diagnostic devices. In the Guidelines for Management of Health Equipment issued by the General Directorate of Health Effort of the Ministry of Health of the Republic of Indonesia) it is stated that medical equipment, as part of medical equipment, is equipment used for therapy, rehabilitation and medical research directly or indirectly. ${ }^{13}$

\subsection{Criteria and Criteria for Critical Factors in Medical Devices}

Based on review of the literature, there are seven major criteria and seven subcriteria to determine the criticality of medical equipment as shown in Table 1.

Table 1. Criteria and Sub Criteria

\begin{tabular}{|c|c|c|c|}
\hline No. & Criteria & Sub Criteria & Sources \\
\hline 1 & $\begin{array}{l}\text { Degree of Complexity of the } \\
\text { maintenance (A) }\end{array}$ & & $\begin{array}{l}\text { Guidelines for Management of } \\
\text { Health Equipment } 2015\end{array}$ \\
\hline 2 & Function (B) & & $\begin{array}{l}\text { Guidelines for Management of } \\
\text { Health Equipment } 2015\end{array}$ \\
\hline \multirow{5}{*}{3} & \multirow{5}{*}{ Risk (C) } & Detectability (C1) & Taghipour et. al (2017) \\
\hline & & Frequency $(\mathrm{C} 2)$ & Taghipour et. al (2017)) \\
\hline & & Downtime (C3) & Taghipouret. al (2017) \\
\hline & & Safety / Safety (C4) & Taghipour et al (2011) \\
\hline & & Repair Costs (C5) & The policy of Eye hospital \\
\hline 4 & $\begin{array}{l}\text { Degree of importance of Mission } \\
\text { (D) }\end{array}$ & Utilisation Rate (D1) & Taghipour et al (2011) \\
\hline 5 & Age(E) & Availability of Alternative (D2) & Taghipour et al (2011) \\
\hline 6 & Recall and User Errors (F) & & $\begin{array}{l}\text { Guidelines for Management of } \\
\text { Health Equipment (2015) }\end{array}$ \\
\hline 7 & Medical Equipment Class (G) & & $\begin{array}{l}\text { Guidelines for Classification of } \\
\text { Health Devices of the Indonesian } \\
\text { Ministry of Health } 2016\end{array}$ \\
\hline
\end{tabular}

\section{Analytical Hierarchy Process (AHP)}

The Analytical Hierarchy Process (AHP) is a functional hierarchy that was developed by Prof. Saaty in the early 1970s, which is used to seek the order of priority of the various alternatives in solving a problem. The AHP consists of several steps : 
1. Define (decomposition) the hierarchy structure of the problem to be solved.

2. Weighting elements at each level of the hierarchy. AHP procedure uses weighting techniques to produce a weighting factor. This weighting factor describes the relative size of the importance of an element compared to the others. Thomas L. Saaty ${ }^{15}$ made a standard rating scale as shown in Table 2.

Table 2. AHP Paired Comparison Scale

\begin{tabular}{|c|l|}
\hline Intensity of Interest & \multicolumn{1}{c|}{ Definition } \\
\hline 1 & Both elements are equally important \\
\hline 3 & One element is a little more important than the other elements. \\
\hline 5 & One element is more important than the other elements \\
\hline 7 & One element is clearly more important than other elements \\
\hline 9 & One element is absolutely important than the other elements \\
\hline $2,4,6,8$ & The values between two consideration values are close together \\
\hline
\end{tabular}

\subsection{Determine the judgment of several experts}

Basically AHP can be used to process data from an expert even though it can be also done by several multidisciplinary experts. Consequently the judgments of these experts need to be checked for consistency one by one. Consistent opinions are then combined using geometric averages :

$$
\overline{X G}=\sqrt[n]{\prod_{i=1}^{n} x_{i}} \text { n=number of expertsXi }=\text { judgement by } 1^{\text {st }} \text { expert }
$$

\subsection{Calculate priorities and weighting consistency.}

The steps taken in calculating priorities and determining weighting consistency are as follows

1. Add the values to the elements of each column.

2. Perform operations dividing each element in the column by the number of columns corresponding.

3. Calculate priority to do the sum of operations for each row and divide it by the number of elements. Then the consistency calculation process is carried out. The process is:

- Multiplying matrices with corresponding priority.

- Add the results of the multiplication multiplier.

- Divide the number of each row with the concerned priority, then add the results.

- Divide the result by the number of elements to get the value $\lambda$ max.

- Calculate the value of the Consistency Index with the formula

$$
(\mathrm{CI})=(\lambda \max -\mathrm{n}) / \mathrm{n}-1)
$$


- Calculating CR Value. Consistency Ratio

$$
(\mathrm{CR})=\mathrm{CI} / \mathrm{RI}
$$

If the consistency value of the ratio is $<0.1$, the input value in the matrix does not need to be revised. Random Index value (RI) is the average value of the index generated randomly from the experiment Thomas L. Saaty (1988) which uses the number of matrices with order 1 to 15 , as shown in Table 3

Table 3. Random Index Value

\begin{tabular}{|l|c|c|c|c|c|c|c|c|c|c|c|c|c|c|c|}
\hline $\begin{array}{c}\text { Matrix } \\
\text { Size }\end{array}$ & $\mathbf{1}$ & $\mathbf{2}$ & $\mathbf{3}$ & $\mathbf{4}$ & $\mathbf{5}$ & $\mathbf{6}$ & $\mathbf{7}$ & $\mathbf{8}$ & $\mathbf{9}$ & $\mathbf{1 0}$ & $\mathbf{1 1}$ & $\mathbf{1 2}$ & $\mathbf{1 3}$ & $\mathbf{1 4}$ & $\mathbf{1 5}$ \\
\hline $\begin{array}{l}\text { Random } \\
\text { Index }\end{array}$ & 0 & 0 & 0.58 & 0.9 & 1.12 & 1.24 & 1.32 & 1.41 & 1.45 & 1.49 & 1.51 & 1.48 & 1.56 & 1.57 & 1.59 \\
\hline
\end{tabular}

\subsection{Set up the grade and intensity of each criteria and sub criteria}

Because the amount of medical equipment is very large and the inventory data is dynamic, absolute measurement techniques are used for ranking medical devices. Absolute assessment can be done if the grade (level) for each criterion and sub-criteria has been determined. If a grade (level) has the highest intensity set to medical equipment related to the criteria, the criteria for this medical equipment must contribute fully to the objectives to be achieved so that the intensity must have a value of 1 . Finally, using absolute AHP, each alternative is evaluated related with each criterion and given the appropriate value ${ }^{2}$. The following is a description of the grade of each criterion and sub-criteria:

1. Maintenance Complexity Criteria have 5 (five) grades, namely equipment that is mostly mechanical, pneumatic, fluid and requires special maintenance (high), Equipment that is considered to require average maintenance and only needs to test the performance of the device (medium), Equipment that only requires visual inspection. Basic checks and minimum requirements for safety (low).

2. Function Criteria consist of 4 grades, namely, Therapy and Life Support, Diagnostics, Analytics, Others

3. Potential failure detection capability consists of 4 grades, which are not detected by regular (very low) inspections, detected by inspection (low), can be seen with the naked eye (medium), and automatically inform (high)

4. Frequency of failure consists of 4 grade, which is often (several events in 1 year), sometimes (several events 1-2 years), rarely (one event in 2-5 years), almost never (one incident 5-20 years).

5. Downtime consists of 4 grade, namely waiting time $>72$ hours (high), waiting time 24 - 72 hours (medium), waiting time $<24$ hours (low)

6. Safety consists of 4 grades, namely death / blindness, injury, therapeutic errors (misdiagnosis), prolonged treatment, no consequences

7. Repair costs consist of 3 grades, namely costs $>50$ Million, costs $>10$ Million - 50 Million, costs $<10$ Million 
8. Utilization rate of device consists of 3 grades, namely usage per week $>24$ hours (high), usage per week 12 - 24 hours (medium), usage per week $<12$ hours (low)

9. The availability of a alternative devices consists of 3 grades, namely the number of substitutes is missing or 1 (high), the number of replacement devices 2-4 (medium), the number of substitutes $>4$ (low)

10. Age of medical equipment consists of 2 grade, which is $<5$ years old (high) and $>5$ years old

11. Recall and user errors consist of 3 grades, namely Total recall $>=1$ per year or Total Hazard alert $>=4$ (high), Total Hazard Alert 2-3 x per year (medium), Total Hazard Alert $1 \mathrm{x}$ per year (low)

12. Medical equipment class consists of 4 grades, namely High Risk (class D), Medium-High Risk (class C), Low-Medium Risk (Class B), Low Risk (Class A)

Calculate the critical score of each medical device: The first step determines the critical score of a medical device by determining the grade on which the medical device is classified. Each value of the intensity corresponding to the grade will be multiplied by the weight of the sub criteria or criteria that are the reference of the grade. After that all the weight of the sub criteria and criteria that have been multiplied by the appropriate grade are summed so that the total value is obtained which becomes the critical score of a medical device.

$$
\begin{gathered}
\prod_{j=1}^{n} a i j \\
\left(\prod_{j=1}^{n} a i j\right) 1 / \mathrm{n} \\
\prod_{j=1}^{n} a i j
\end{gathered} \frac{\begin{array}{c}
\left(\prod_{j=1}^{n} a i j\right) 1 / \mathrm{n} \\
\text { Intensitas }=\mathrm{Vi} / \max (\mathrm{Vi})
\end{array}}{}
$$

\section{$4 \quad$ Results and Discussion}

\subsection{Medical Equipment Criteria Diagram}

The AHP hierarchy for determining the critical weight of medical equipment consists of seven criteria and seven sub-criteria as shown in Figure 1. 

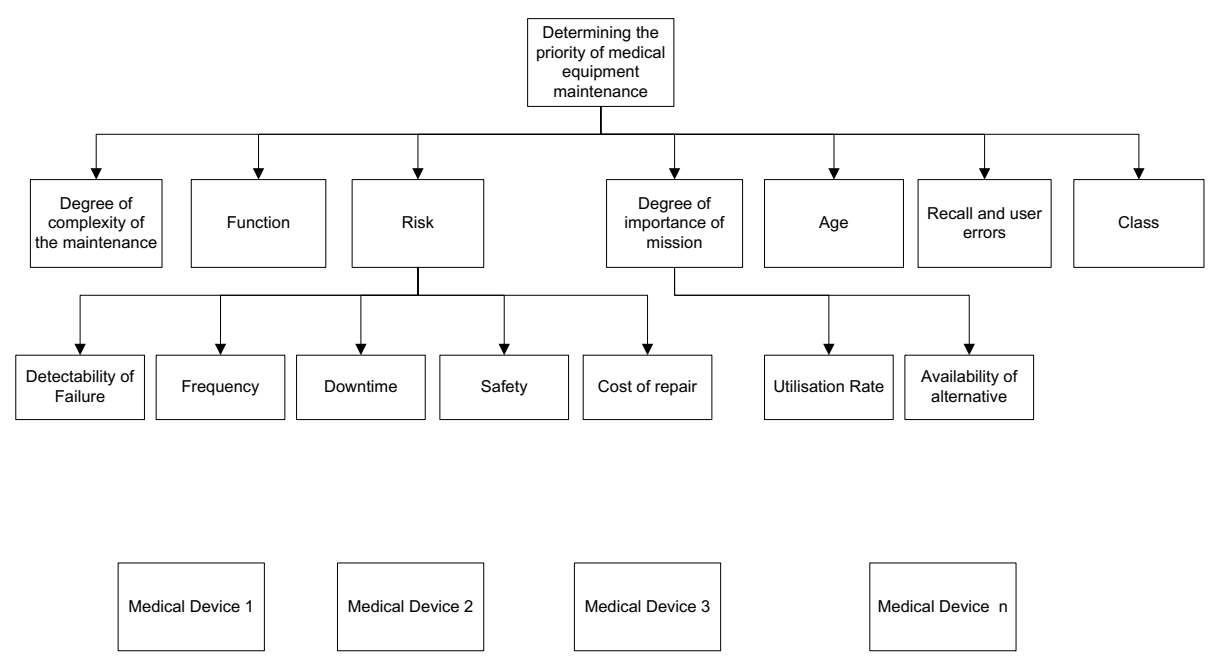

Fig. 1. AHP Hierarchy of Determining the priority of medical equipment

\subsection{Analysis of Pair wise comparison matrix}

The questionnaire assessment criteria that were filled in by the three experts were combined to obtain geometric mean by using equation (1).

Table 4. Matrix of Merging Paired Valuation

\begin{tabular}{|c|c|c|c|c|c|c|c|}
\hline Criteria & A & B & C & D & E & F & G \\
\hline A & 1 & 0.693 & 0.281 & 0.405 & 0.222 & 0.5107 & 0.40534 \\
\hline B & 1,443 & 1 & 0.228 & 0.9997 & 0.793 & 0.693 & 0.281 \\
\hline C & 3,559 & 4,386 & 1 & 3 & 3,979 & 4,762 & 2,154 \\
\hline D & 2,469 & 1 & 0.333 & 1 & 0.48 & 1,442 & 0.441 \\
\hline E & 4,504 & 1,261 & 0.251 & 2,083 & 1 & 0.693 & 0.251 \\
\hline F & 1,958 & 1,442 & 0.2098 & 0.693 & 1,442 & 1 & 0.523 \\
\hline G & 2,465 & 3,557 & 0.4527 & 2,267 & 3,979 & 1,912 & 1 \\
\hline
\end{tabular}

A: Degree of complexity of the maintenance

B: Function

C: Risk

D: Degree of importance of mission

E: Age D

$\mathrm{F}$ : Recall and User Errors

E: Class

The Matrix normalization including the priority vector weight is obtained as shown in Table 5.

Table 5. Matrix Normalization and Priority Vector

\begin{tabular}{|c|c|c|c|c|c|c|c|c|c|}
\hline Criteria & A & B & C & D & E & F & G & Total & Priority Vector \\
\hline A & 0.057 & 0.052 & 0.102 & 0.039 & 0.019 & 0.046 & 0.080 & 0.395 & 0.057 \\
\hline B & 0.083 & 0.075 & 0.083 & 0.096 & 0.067 & 0.063 & 0.056 & 0.521 & 0.075 \\
\hline
\end{tabular}




\begin{tabular}{|c|c|c|c|c|c|c|c|c|c|}
\hline C & 0.205 & 0.329 & 0.363 & 0.287 & 0.335 & 0.432 & 0.426 & 2,376 & 0.340 \\
\hline D & 0.142 & 0.075 & 0.121 & 0.096 & 0.040 & 0.131 & 0.087 & 0.692 & 0.099 \\
\hline E & 0.259 & 0.095 & 0.091 & 0,199 & 0.084 & 0.063 & 0.050 & 0.841 & 0.121 \\
\hline F & 0.112 & 0.108 & 0.076 & 0.066 & 0.121 & 0.091 & 0.103 & 0,679 & 0.095 \\
\hline G & 0.142 & 0.267 & 0.164 & 0.217 & 0.335 & 0.174 & 0.198 & 1,496 & 0.214 \\
\hline
\end{tabular}

Table 6. Pairing Comparative Assessment Risk Sub Criteria

\begin{tabular}{|l|c|c|c|c|c|}
\hline \multicolumn{1}{|c|}{ Sub Criteria } & C1 & C2 & C3 & C4 & C5 \\
\hline C1 & 1 & 0.481 & 0.822 & 0.281 & 3,302 \\
\hline C2 & 2,080 & 1 & 1 & 0.164 & 3,915 \\
\hline C3 & 1,216 & 1 & 1 & 0.178 & 1.71 \\
\hline C4 & 3,557 & 6,084 & 5.595 & 1 & 5,646 \\
\hline C5 & 0.3023 & 0.255 & 0.585 & 0.177 & 1 \\
\hline
\end{tabular}

Table 7. Determination of Priority Vector Risk Sub-Criteria

\begin{tabular}{|l|c|c|c|c|c|c|c|}
\hline Sub Criteria & C1 & C2 & C3 & C4 & C5 & Total & Priority Vector \\
\hline C1 & 0.1226 & 0.0545 & 0.0913 & 0.1561 & 0.21202 & 0,6365 & 0.125 \\
\hline C2 & 0.255 & 0.1134 & 0.111 & 0.091 & 0.251 & 0.822 & 0.179 \\
\hline C3 & 0.149 & 0.1134 & 0.1111 & 0.0992 & 0.1098 & 0.5826 & 0.114 \\
\hline C4 & 0.4361 & 0.6898 & 0.6215 & 0.5551 & 0.3626 & 2,6652 & 0.524 \\
\hline C5 & 0.0371 & 0.0289 & 0.065 & 0.0983 & 0.0642 & 0.2936 & 0.058 \\
\hline
\end{tabular}

C1: Detectability

C2: Frequency of failure

C3: Downtime

C4: Safety

C5: Repair costs

Table 8. Comparative Judgement Based on Sub-Criteria of Importance of Mission

\begin{tabular}{|l|c|c|c|c|}
\hline \multicolumn{1}{|c|}{ Sub Criteria } & Utilization & Availability of Alternative & Total & Priority Vector \\
\hline Utilization & 0.542 & 0.542 & 1.084 & 0.542 \\
\hline Availability of Substitutes & 0.458 & 0.457 & 0.915 & 0.458 \\
\hline
\end{tabular}

Then, the Consistency Ratio (CR) calculation is done using the equation (2) and (3) with the value of $\mathrm{CR}=$ $0.081>0.1$ which would mean i consistent ratings as required matrix Saaty (2008)

\subsection{Determining grade and intensity for criteria and sub-criteria}

Step 1 Matrix evaluates the comparison of grades based on the third assessment expert (a ij for $\mathrm{I}=1, \ldots, 4, j=1, \ldots, 4$ )

Table 9. Assessment Grade and Critical Intensity a Function

\begin{tabular}{|c|c|c|c|c|}
\hline Grade & Therapy (Healing) & Diagnostic & Analytic & Etc \\
\hline Therapy & 1 & 4.82 & 5,739 & 8,277 \\
\hline Diagnostic & 0.207 & 1 & 4,718 & 6,257 \\
\hline Analytic & 0.174 & 0.212 & 1 & 5,593 \\
\hline Etc & 0.121 & 0.16 & 0.179 & 1 \\
\hline
\end{tabular}


Step 2. The weight of each grade is obtained by using equation (4) as follows:

Therapy $=1 \times 4,82 \times 5,739 \times 8,277=228,958$

Diagnostics $=0.207 \times 1 \times 4.718 \times 6.257=6,11$

Analytic $=0.174 \times 0.212 \times 1 \times 5.593=0.206$

Others $=0.121 \times 0.16 \times 0.179 \times 1=0.0035$

The calculation results of each grade element in step 2 above then according to equation (5) are given a square root 4 (according to the number of grades) with the following results:

Therapy $=3,89 ;$ Diagnostics $=1,572 ;$ Analytic $=0.674 ;$ Others $=0.243$

All results of the fourth root values obtained are then added together

$3,89+1,572+0,674+0,243=6,379$

Thus the normalization of each element grade obtained by using equation (6) sebag a i follows:

- Therapy $=3.89 / 6.379=0,61$

- Diagnostics $=1,572 / 6,379=0,245$

- Analytic $=0.674 / 6.379=0.106$

- Others $=0.243 / 6.379=0.038$

Step 3.The intensity of each grade are obtained by using equation (7)

Therapy $=1 ;$ Diagnostics $=0.402 ;$ Analytic $=0.174 ;$ Others $=0.062$

Table 10. Intensity of Degree of complexity of the Maintenance

\begin{tabular}{|l|l|c|}
\hline Grade & \multicolumn{1}{|c|}{ Description } & Intensity \\
\hline High & Equipment that is mostly mechanical, pneumatic, fluid and needs special maintenance & 1 \\
\hline Medium & $\begin{array}{l}\text { Equipment that is considered to require average maintenance and only needs to test the } \\
\text { performance of the tool }\end{array}$ & 0.05 \\
\hline Low & $\begin{array}{l}\text { Equipment that only requires visual inspection. Basic checks and minimum safety } \\
\text { requirements }\end{array}$ & 0.015 \\
\hline
\end{tabular}

Table 11. Intensity of Detectability

\begin{tabular}{|l|l|c|}
\hline \multicolumn{1}{|c|}{ Grade } & \multicolumn{1}{|c|}{ Description } & Intensity \\
\hline Very Low & Not Detected by regular inspections & 1 \\
\hline Low & Detected with Inspection & 0.393 \\
\hline Medium & Can be seen with the naked eye & 0.15 \\
\hline High & Automatically inform & 0.071 \\
\hline
\end{tabular}

Table 12.

Intensity of Frequency of failure

\begin{tabular}{|l|l|c|}
\hline \multicolumn{1}{|c|}{ Grade } & \multicolumn{1}{|c|}{ Description } & Intensity \\
\hline Often & Often (several events in 1 year) & 1 \\
\hline Sometimes & Sometimes (some events 1-2 years) & 0,384 \\
\hline Rarely & Rarely (one event in 2-5 years) & 0.13 \\
\hline Almost no & Almost never (one incident 5-20 years) & 0,057 \\
\hline
\end{tabular}


Table 13. Intensity of Downtime

\begin{tabular}{|l|l|c|}
\hline \multicolumn{1}{|c|}{ Grade } & \multicolumn{1}{|c|}{ Description } & Intensity \\
\hline High & Waiting Time $>72$ hours & 1 \\
\hline Medium & Waiting Time $24-72$ hours & 0,306 \\
\hline Low & Waiting Time $<24$ hours & 0,077 \\
\hline
\end{tabular}

Table 14.

Intensity of Safety

\begin{tabular}{|l|c|}
\hline \multicolumn{1}{|c|}{ Grade } & Intensity \\
\hline Death / Blindness & 1 \\
\hline Injury & 0,609 \\
\hline Therapy errors / misdiagnosis & 0,386 \\
\hline Prolonged treatment & 0,232 \\
\hline There are no consequences & 0,072 \\
\hline
\end{tabular}

Table 15. Intensity of Repair costs

\begin{tabular}{|l|l|c|}
\hline \multicolumn{1}{|c|}{ Grade } & \multicolumn{1}{|c|}{ Description } & Intensity \\
\hline High & Cost $>$ 3500 USD & 1 \\
\hline Medium & Cost $>700-3500$ USD & 0.345 \\
\hline Low & Cost of $<700$ USD & 0.119 \\
\hline
\end{tabular}

Table 16. Intensity of Utilisation Rate

\begin{tabular}{|l|l|c|}
\hline \multicolumn{1}{|c|}{ Grade } & \multicolumn{1}{|c|}{ Description } & Intensity \\
\hline High & Usage per week $>24$ hours & 1 \\
\hline Medium & Usage per week 12-24 hours & 0.287 \\
\hline Low & Usage per week $<12$ hours & 0.088 \\
\hline
\end{tabular}

Table 17. Intensity of Availability of Alternative Device

\begin{tabular}{|l|l|c|}
\hline \multicolumn{1}{|c|}{ Grade } & \multicolumn{1}{|c|}{ Description } & Intensity \\
\hline High & Number of substitute 1 or none & 1 \\
\hline Medium & Number of replacement devices 2-4 & 0,306 \\
\hline Low & Number of substitutes $>4$ & 0,106 \\
\hline
\end{tabular}

Table $18 . \quad$ Intensity of Age

\begin{tabular}{|l|l|c|}
\hline \multicolumn{1}{|c|}{ Grade } & \multicolumn{1}{|c|}{ Description } & Intensity \\
\hline High & $>5$ years old & 1 \\
\hline Low & $<5$ years old & 0,195 \\
\hline
\end{tabular}

Table 19. Recall and User Errors

\begin{tabular}{|l|l|c|}
\hline \multicolumn{1}{|c|}{ Grade } & \multicolumn{1}{|c|}{ Description } & Intensity \\
\hline High & Total recall $>=1$ per year or Total hazard alert> =4 & 1 \\
\hline Medium & Total Hazard Alert 2-3 x per year & 0.29 \\
\hline Low & Total Hazard Alert 1 x per year & 0,098 \\
\hline Zero & There is no & 0 \\
\hline
\end{tabular}


Table 20. $\quad$ Class of Devices

\begin{tabular}{|l|l|c|}
\hline \multicolumn{1}{|c|}{ Grade } & \multicolumn{1}{c|}{ Description } & Intensity \\
\hline Class D & High risk & 1 \\
\hline Class C & Risk of Medium-High & 0.394 \\
\hline Class B & Low-moderate risk & 0.145 \\
\hline Class A & Low risk & 0.065 \\
\hline
\end{tabular}

\subsection{Determining medical equipment ranking}

To determine the ranking of medical equipment, total score for each medical devices must be calculated. This total score was obtained based on the calculation of the criteria weight, sub-criteria weight, and intensity in accordance with the category of medical devices. The following is shown how the calculation of the critical score of Eximer Laser is based on the criteria weight, the criteria and grade intensity as in Table 21

Table 21. Calculation of Total Score of Excimer Laser

\begin{tabular}{|l|l|}
\hline \multicolumn{1}{|c|}{ Criteria } & \multicolumn{1}{|c|}{ Sub Criteria } \\
\hline Degree of Complexity of the Maintenance $(0.057) * 1$ & \\
\hline Function $(0,075) * 1$ & \\
\hline \multirow{5}{*}{ Risk $(0.34)$} & Detectability $(0.125) * 1$ \\
\cline { 2 - 2 } & Frequency of Failure $(0.179) * 0.384$ \\
\cline { 2 - 2 } & Downtime $(0.114) * 1$ \\
\cline { 2 - 2 } & Safety $(0,524) * 1$ \\
\cline { 2 - 2 } Degree of Importance of Mission $(0.099)$ & Repair costs $(0.058) * 1$ \\
\hline Age $(0.121) * 1$ & Utilisation $(0.542) * 1$ \\
\hline Recall and User Error $(0.095) * 0.098$ & \\
\hline Tool Class $(0.214) * 1$ & \\
\hline
\end{tabular}

$(0.057 \times 1)+(0.075 \times 1)+((0.034((0.125 \times 1)+(0.179 \times 0.384)+(0.114 \times 1)+(0.524 \times 1)+(0.058 \times$ $1))+((0.0099((0.542 \times 1)+(0.458 \times 1))+(0.121 \times 1)+(0.095 \times 0.098)+(0.214 \times 1)=\mathbf{0 . 8 7 7}$

Table 22. Calculation of the Total Score of Retinometer

\begin{tabular}{|l|l|}
\hline \multicolumn{1}{|c|}{ Criteria } & \multicolumn{1}{|c|}{ Sub Criteria } \\
\hline Degree of complexity of the maintenance $(0.057) * 1$ & \\
\hline Function $(0.075) * 0.402$ & \\
\hline \multirow{5}{*}{ Risk $(0.34)$} & Detectability $(0.125) * 0,393$ \\
\cline { 2 - 2 } & Frequency of failure $(0.179) * 0,384$ \\
\cline { 2 - 2 } & Downtime $(0.114) * 0.306$ \\
\cline { 2 - 2 } & Safety $(0.524) * 0.232$ \\
\cline { 2 - 2 } Interest of Mission Tools $(0.099)$ & Repair costs $(0.058) * 0.119$ \\
\hline Age of Tool $(0.121) * 1$ & Tool Utilization $(0.542) * 0.287$ \\
\cline { 2 - 2 } Recall and User Error $(0.095) * 0.098$ & Keters of Replace Equipment $(0.458) * 0.306$ \\
\hline Tool Class $(0.214) * 0.145$ & \\
\hline
\end{tabular}


The total score is $(0.057 \times 1)+((0.075((0.125 \times 0.393)+(0.179 \times 0.384)+(0.114 \times 0.306)+(0.524 \times$ $0.232)+(0.058 \times 0.287))+((0.099((0.542 \times 0.287)+(0,0458 \times 0.306))+(0.121 \times 1)+(0.095 \times 0.098)+$ $(0.214 \times 0.145))=\mathbf{0 . 3 7 3}$

From the two examples above it can be concluded that the Lasik surgical device (schwind) has a criticality score of 0.877 which is greater than the Retinometry tool of 0.373 . Thus the Schwind surgical device has higher priority for the maintenance of medical equipment compared to the Retinometer.

The result of ranking 21 devices are shown in Table 23

Table 23. Ranking of 21 Medical Devices for maintenance decision

\begin{tabular}{|l|c|}
\hline \multicolumn{1}{|c|}{ Name of Devices } & Total Score \\
\hline Excimer Laser & 0,877 \\
\hline Retinal Laser & 0,675 \\
\hline YAG Laser 11l & 0,657 \\
\hline Defibrilator & 0,634 \\
\hline Patient Monitor & 0,540 \\
\hline ECG-6 CHANNEL KENZ & 0,482 \\
\hline Slit Lamp Camera Video & 0,441 \\
\hline Humphrey 111 860 & 0,437 \\
\hline Oculus Pentacam HR 70900 & 0,437 \\
\hline HRT II & 0,437 \\
\hline OCT Cirrus 5000 & 0,426 \\
\hline Specular Microscope & 0,399 \\
\hline Slit Lamp BP 900 & 0,389 \\
\hline IOL Master 700 & 0,378 \\
\hline Nebulizer & 0,376 \\
\hline Retinometer & 0,373 \\
\hline USG Ellex Eye Cub & 0,339 \\
\hline Foto fundus TRC 50-DX & 0,339 \\
\hline Tensimeter & 0,281 \\
\hline Digital Baby Scales & 0,238 \\
\hline Autolensmeter & 0,154 \\
\hline
\end{tabular}

\subsection{Discussion}

Based on the calculation of the assessment of pair wise comparisons between criteria, the criteria of Risk has the highest value of 0.34 , followed by the criteria ofClass with a value of 0.214 ; Age with 0.121; Degree of Importance of Mission with 0.99 ; Recall and user errors with 0.095 ; Function 0.75 ; and Degree of complexity of the Maintenance with 0.057 . This means that the risk is the most important criterion considered by biomedical technicians in determining the priority of maintaining a medical device. This was confirmed by $\mathrm{Hyman}^{16}$ who stated that clinical engineering believes that risk is not the only criterion for medical devices, although risk is the most important criterion. The patient safety factor that is directly related to the risk of medical equipment is the goal of the national and international accreditation standards of hospitals so that it reinforces the basis of why the risk has the highest weight. Based on the calculation of the assessment of pair wise comparisons between 
the sub criteria of the Risk criteria, sub-criteria Safety has the highest, followed by Frequency of Failure, Detectability, Downtimeand Cost of repair. This means subcriteria Safety is the most important sub criteria in risk assessment by biomedical technicians in determining the priority of maintenance of a medical device. This has reinforced the previous reason why risk has the highest weight among criteria, namely the importance of the safety factor.

Based on the assessment of priority score among the sub-criteria which are part of the criteria of the Mission Level of Interest, it is known that the sub-criteria for tool utilization rate get the highest value of 0.542 followed by the sub-criteria for the availability of alternative devices with 0.458 . This result shows that utilization or how often a medical instrument used is considered more important than the availability of alternative devices in the process of health care in hospitals.

Based on intensity value of each criteria and sub-criteria the maximum intensity value for each category of criteria and sub-criteria is 1 . Value of intensity is an important part that is taken into account together with the weighting of criteria and subcriteria to determine the order of priority of each medical devices. Each alternative (medical devices) is evaluated in relation to each determination of the criteria and given a description of the appropriate grade. Examples taken for the assessment of critical weights were excimer laser device with a critical weight of 0.877 greater than the critical weight of retinometer. This means that the excimer laser devices has higher priority than retinometer in the maintenance program of medical devices.

\section{Conclusions}

1. The method of decision making based on multi criteria can be used to determine priorities in maintaining medical equipment. The priority order of medical equipment is determined by the results of the assessment of the critical score of a medical device

2. Hospital management should plan a large number of medical equipment maintenance programs based on priority scale so that resources are more focused on medical devices that have high and medium criticality.

\section{$6 \quad$ References}

[1] Triantaphyllou, E. Multi-Criteria Decision Making Methods: A Comparative Study. Kluwer Academic Publishers, Dordrecht; 2000.

[2] Saaty TL. Decision Making with the Analytic Hierarchy Process. International Journal of Services Sciences 2008; 1(1): 83-98

[3] Taghipour S. Reliability and Maintenance of Medical Devices (Thesis). Department of Mechanical and Industrial Engineering University of Toronto; 2011

[4] TaghipourS, BanjevicD, Jardine AKS. Prioritization of Medical Equipment for Maintenance Decision J. Oper. Res. Soc 2011 Sep; 62(9) : 1666-87 
[5] Ivlev I, Kneppo P, Bartak M. Multicriteria Decision Analyssis: A Multifaceted approach to medical equipment management, Technological Economic Development of Economy 2014; 20 (3). https://doi.org/10.3846/20294913.2014.943333

[6] Jamshidi A, Abbasgholizadef Rahimi S, Ait-kadi D, Ruiz A. A Comprehensive FuzzyRiskBased Maintenance Framework for Prioritization of Medical Devices, Applied Soft Computing 2015; 32. https://doi.org/10.1016/j.asoc.2015.03.054

[7] Ben Houria Z, Masmoudi M, Al Hanbali A, et al. Quantitative Techniques for Medical Equipment Maintenance Management, European J of Industrial Engineering 2017 Jan (6 p) https://doi.org/10.1504/ejie.2016.081017

[8] Dhillon BS. Maintability, Maintenance, and Reability for Engineering. Taylor and Francis Group, New York: LLC ; 2006

[9] Heizer R, Reinder B. Operation Management, $8^{\text {th }}$ Edition, Pearson Prentice Hall. Ner Jersey; 2006

[10] Sehwarat MS, Narang JS. Production Management, Nai Sarak, Dhanpahat RAI Co; 2001

[11] Minister of Health RI. Regulation of Indonesian Minister of Health No. 1191/MENKES/PER/VIII/2010 Concerning Distribution of Medical Devices; 2010

[12] Minister of Health RI. Decree of Indonesian Minister of Health No.118/MENKES/SK/IV/2014 Concerning the Compendium of Medical Devices, consisting of 3 types, namely Electromedical, Non Electromedical and In Vitro Diagnostic Devices; 2014

[13] General Directorate of Health Effort of the Ministry of Health of the Republic of Indonesia. Guidelines for Management of Health Equipment; 2015

[14] Ministry oh Health RI. Guidelines for Classification of Distribution Licenses for Medical Services; 2016

[15] Saaty TL. The Analytical Hierarchy Process, McGraw-Hill; 1980

[16] Youssef, NF, Hyman WA. A Medical Device Complexity Model: A New Approach to Medical Equipment Management, J. Clin. Eng 2003 ; 34(2) : 94-98

\section{Authors}

Alfa Omega Hutagalung:Master in Industrial Engineering at Mercu Buana University, Ibukota Jakarta. E mail alfao.htg@gmail.com

Sawarni Hasibuan: Master in Industrial Engineering, Mercu Buana University, Ibukota Jakarta. E mail sawarni@mercubuana.ac.id

Article submitted 2019-03-09. Resubmitted 2019-04-27. Final acceptance 2019-05-06. Final version published as submitted by the authors 